\title{
Action research into the use of popular music: A goldmine worth exploring in the ELT secondary-school classroom?
}

\author{
av Agnes Scott Langeland
}

\begin{abstract}
Conducting action research is an excellent way for teachers and teacher trainers to pursue their professional development inside the classroom and for language learners to take part in small-scale research projects. This article presents a study where action research was used in the teaching and learning of English in a Norwegian upper-secondary school initiated by a teacher trainer and implemented in collaboration with a partner teacher. A class of thirty first-year pupils on a general studies programme took part in a project to investigate lexicogrammatical or multimodal features in a selection of popular music while working towards achieving some of the competence aims in the English subject curriculum. The project involved dividing the learners into two groups each of which followed a different approach to investigating the lyrics and, in the case of one group, also the videos. The same written assignment was given to both groups to see if similar or diverging results emerged that might be related to the different approaches used. The learners were also given a pre-project and a post-project questionnaire to probe their thoughts and reactions to the learning process. Both approaches made use of music performances on YouTube; these represent a rich, multimodal resource appreciated by adolescents but tending to be underexploited by English language teachers. Besides presenting the actual study, this article is intended as a step-by-step guide for teachers who would like to implement similar action in their own classrooms.
\end{abstract}

\section{Introduction}

Currently many teachers and teacher trainers are taking an interest in the use of action research in the classroom in their pursuit of professional development. They see this kind of research as a way to develop their teaching while involving pupils in a classroom study that sets out to investigate aspects of their learning. Action research (AR) has consequently become an increasingly popular way to carry out classroom-based investigation into a specific problem or area of interest for practioners (Hughes, Marjan \& Taylor 2012). Since the design of such studies is highly flexible, it provides a practical format to test out some hypothesis on a small-scale. 
AR has been defined by Grabe and Stoller as "a form of teacher-initiated enquiry in which teachers look systematically and critically at their own classrooms to get an insider's view of the teaching and learning process" (2002: 3). This is in line with the Education Act which states that it is an aim to "stimulate, use and further develop each teacher's competence" (2005: $§ 10.8$, cited in The Quality Framework, 2006: 2, my translation). It is also in line with the views expressed by the Organisation for Economic Cooperation and Development (OECD) in a report called Teachers Matter, where action research is seen as one way of answering the need for teachers "to be active agents in analysing their own practice in the light of professional standards, and their own students' progress in the light of standards for student learning" (OECD 2005:10). In other words, this kind of research makes it possible for both teachers and pupils, but also teacher trainers who take part, to benefit by becoming observers and agents who seek answers to certain questions.

Within the field of teaching English as a second or additional language, such research projects can test out various hypotheses concerning second language skills, or analyse specific aspects or developments in the English language, or experiment with different methods in English language teaching and learning (ELT). Several researchers have published studies of action research or models that provide a basis for designing ELT action research (Oxford 2011; Lantolf and Thorne 2006; Grabe and Stoller 2002; James 2001). Besides outlining studies that have been carried out looking into first language (L1) and second language (L2) reading, Grabe and Stoller present many interesting models for testing vocabulary development, reading skills and student interest by setting up "a set of research questions that can guide meaningful action research projects" (2002: 202). Their intention is that these can be adopted or adapted by L1 or L2 language teachers, and their models led to the conception of the AR project described in this article. The project addresses the need for learners to develop more awareness of lexico-grammatical and multimodal features and the need for teachers and teacher trainers to try out new teaching practices. Firstly, the rationale, the research question and the design of the project will be presented, and then the findings and a discussion of the results, and finally some concluding remarks on possible implications for language classrooms and further research.

\section{Rationale}

The project is designed for pupils learning English as an L2 at secondary level. The project was carried out in a class of thirty pupils in the first year of a general studies programme at a Norwegian upper secondary school, by the author of this article, a teacher trainer in ELT and a partner teacher, who is the class teacher in English ${ }^{1}$. Many learners in this age group lose interest in school work due to the lure of extracurricular interests; a main interest for a large number is popular music in one or several of its genres. Popular music is here understood in a

\footnotetext{
${ }^{1}$ A big vote of thanks goes to Inger Marit Jahr, the partner teacher, without whom there would have been no project. Her enthusiasm played a part throughout the project, and her comments on this article were a great help.
} 
wide sense covering diverse musical genres, as distinct from the narrower use of the word 'pop' as a genre in itself. Within the popular music field there is a wealth of material and a tremendous variety to draw upon: pop, rock, country, blues, hard rock, rap and hip-hop, to name some of the genres on the Amazon MP3 website (2013).

Analysing the lyrics of a selection of contemporary popular music can be a motivating language learning activity since using teaching materials that relate to learners' everyday lives and experiences is generally a motivational factor (Dörnyei 2001: 63), although this will not be true for those pupils who only like other forms of music. The study should likewise increase motivation through appealing to pupils' different learning styles on account of the highly aural and visual components. Therefore, one theory behind the design of the study is that employing popular music as a resource will stimulate the learning environment for this particular group of learners. Another is the desire to provide an opportunity for pupil, teacher and teacher trainer development through new teaching and learning procedures that can lead to reflection and change, in accordance with Oxford's claim that: " $(\mathrm{t})$ he purpose of action research is generally to create new insights for positive educational change ..." (2011:234). The study also draws on Halliday and Matthiessen's theory of systemic functional grammar, which stresses the importance of contexts of use to "the relation between choice of words and choice of grammatical categories" (2004: 46), in this instance, through realizations in popular music lyrics. In addition, bringing popular music videos into the ELT classroom via YouTube can provide a highly stimulating context for many adolescent learners and make it possible to explore visual modalities as a semiotic resource.

The design also takes into account Vygotsky's sociocultural theory (1978), which points to the importance of social interaction in cognitive development, and also Krashen's affective filter hypothesis concerning the positive effect of removing stress from the learning environment (1987). The interactive nature of music videos may promote language learning because, as Schoepp maintains: "Songs are one method for achieving a weak affective filter" (2003:1), and consequently can be a positive ingredient in L2 learning. Moreover they help to vary the learners' encounters and deepen their understandings of new words and expressions, which are acknowledged ways of attaining active mastery of new vocabulary (Nation 2002; Gairns \& Redman 1986).

Another key factor in the project is that it can provide a motivating way of working towards attaining some of the competence aims in the English subject curriculum in The National Curriculum for Knowledge Promotion in Primary and Secondary Education and Training, generally referred to as LKO6 (2006). All three main areas in the English subject curriculum, namely "Language learning", "Communication" and "Culture, society and literature", are targeted since the study exploits: "various situations, work methods and strategies to learn English" by bringing in the popular music scene; it involves learners being able to "understand and use a wide general vocabulary" and "describe and evaluate the effects of different verbal forms of expression" by studying language use in pop lyrics; it also requires them to "discuss and elaborate on English texts from a selection of different genres" by investigating musical genres and visual devices on videos (LK06 2006: 5-6). These are all important attainment targets (ATs) in English at upper secondary level, in other words after 11-12 years of English instruction. 


\section{Research question}

The expectation was that the two different approaches would lead to diverging results on the written assignment and on the questionnaires for the two groups of pupils. The research question therefore investigates the consequences of the two different approaches that were adopted to analysing pop songs, based on the data from the respondents' answers on the writing task and the two questionnaires.

Are there any divergences in the results that may be attributed to the different approaches employed in analysing a selection of pop songs and videos?

\section{Design}

The study incorporated multiple methods of investigation and data collection. The method underpinning the study was the implementation of two analytical approaches to the same set of popular music lyrics and videos. In addition, the learners were given a pre-study and a post-study questionnaire and a written assignment. These mixed methods were adopted as a form of triangulation, which is a means of establishing validity, defined by Cohen et al. as 'the use of two or more methods of data collection' (2011: 195) so that different sources of data may enable cross-checking of results (Teddlie \& Reynolds 2000:116).

The first analytical approach was lexico-grammatical in form, based mainly on analysis of features of the lyrics, though the videos were also viewed; the second analytical approach was multimodal in form as it was based on analysis of the lyrics in relation to the music videos. These are designated Approach 1 and Approach 2.

Before the AR project started, the partner teacher told the pupils about the design and asked if they were interested in participating on it, which they were. They felt quite motivated at the prospect of doing something "different" in some of their English lessons. In addition, they were informed that what they learned and experienced on the project was relevant to the ATs in the English subject curriculum since the terminology they learned while analysing these song texts would be useful in their work with short stories, poetry and films. This motivation and knowledge about the project were important factors for successful implementation. The partner teacher divided the thirty learners into two groups of fifteen pupils, Group A and Group B. The division was random and not related to competence in English, and consequently, there were pupils with high and low levels of proficiency in both groups. Group A, led by the partner teacher, followed Approach 1 in their analysis of the texts, while Group B, led by the teacher trainer, pursued Approach 2.

The project extended over five single lessons of English over a four-week period; this included an initial introductory lesson for the whole class, when different analytic features from the two approaches were illustrated using Text 1 and the accompanying video on YouTube (see below and references). The next three lessons were devoted to group analyses of three new song texts (see Texts 2 - 4 below). In the fifth and final lesson, both groups were given the same written assignment related to a fifth song text (see Text 5 below). The pupils were given a questionnaire after both the first and last sessions. 
The five different song lyrics and videos selected by the partner teacher and the teacher trainer were:

Text 1: 'From Miami to Ibiza' performed by Tinie Tempah and featuring Swedish House Mafia (2010);

Text 2: 'Written in the stars' performed by Tinie Tempah and featuring Erik Turner (2010);

Text 3: 'If I were a boy’ performed by Beyoncé Knowles (2009);

Text 4: 'Amazing' performed and written by Kanye West and featuring Young Jeezy (2009);

Text 5: 'Firework' by Katy Perry (2012).

(See appendix 1 for the lyrics of Text 1 and the URLs in the references for the other texts and the videos) These were chosen because they all contain some idiomatic, non-standard and intertextual usage, and all are performed on video on YouTube. In addition, the songs, which are performed by well-known British, Caribbean and American song artists, represent a range of contemporary genres in popular music: urban pop/europop in Text 1 , soul/rap in Text 2, R\&B in Text 3, R\&B/hip-hop in Text 4 and disco-rock in Text 5; they have thematic content related to the challenges of growing up and romantic involvement which were considered relevant and familiar in this age-group.

Three factors must be mentioned that may have impacted on the study: firstly each group was led by a different teacher, secondly many of the pupils might have seen the videos before, and thirdly individual preferences in music were overlooked. In order to minimize the first of these possible limitations, each lesson was discussed in detail in advance by the two teachers. The possible limitations of the other two factors were hopefully equally distributed in the two groups.

In the next section the procedures involved in each approach are described in greater detail, the questionnaire procedures are given, and the final writing task and assessment criteria are presented.

\section{Procedure for Approach 1}

Group A analysed the pop texts in relation to the incidence of lexico-grammatical features, instantiated in idiomatic usage, non-standard English and intertextual allusions. Step one involved listening to the song being played on YouTube with the lyrics provided. During and after a replay, the learners were asked to identify instances of the following in the text: 1) full idioms or idiomatic expressions, 2) non-standard usage, and 3) intertextual references. Afterwards, they were asked to compare their findings with a partner in preparation for a whole group discussion. The next step was to study their findings by trying to explain the meaning of the idioms and change them into congruent, more literal expressions, convert any non-standard structures into the equivalent standard English forms and lastly discuss intertextual features in terms of cultural, personal and literary references and the theme of the 
song. Studying these lexico-grammatical features in pop lyrics might open learners' eyes to using such strategies in order to create an authentic "artistic voice" in their own texts.

In the introductory lesson, Text 1 was used to exemplify what the pupils should identify and explain, using the following as examples: In Text 1, the expression "that's standard procedure from Miami to Ibiza" is an idiom whose literal meaning is that something is normal behavior in places like these. An example of non-standard usage in Text 1 is: "She pose for AHM", where the present tense $-S$ inflection of the verb is dropped, which is common in urban social dialects in the UK and the US; here standard English would have used: "She poses ...". Intertextuality was also exemplified in Text 1; the words: "Scene one/ Everybody get in your positions/....Take one /Action" alludes to the kind of instructions used by a film director. Other intertextual references in Text 1 are to specific, cultural status artefacts, e.g. "my bold BB" and "a black BM", in other words a BlackBerry mobile phone and a BMW car. Another kind of intertextual reference found in pop texts is to other song artists, song lyrics or works of literature, commonly as an acknowledgement of their influence on the song writer. In Text 1, Tinie Tempah overtly acknowledges the group Swedish House Mafia when he says he is "raving with SHM".

\section{Procedure for Approach 2}

Approach 2, which was followed by Group B, is partly based on an adaptation of a close listening method proposed by Spaventa (1983: 33-34). Approach 2 also follows Mehta, in the belief that: 'Careful listening to the words may be a good option in teaching vocabulary items in a heterogenic classroom' (2009:1) as vocabulary had to be recalled and discussed. This group listened to each piece of music without initially seeing the text while watching the music video. Instead of reading the text to identify specific linguistic features, Group B were to hone their listening skills and powers of visual observation by focusing on two areas: firstly, by using close listening to recall and reconstruct some of the text, and secondly, by analysing the visual effects in the video in relation to the theme of the song.

The first step was that pupils noted down words while they listened the first time in order to reconstruct the chorus of the text, first individually and then in a whole group session. During a second playing, missing words had to be inserted into a gapped version of the rest of the song text, and the correct items discussed afterwards in the group. The next step involved a third replay to study the video. The aim was to identify any links between the scenes in the video with the theme expressed in the lyrics. A set of guidelines was provided so learners had cues for which visual effects they should try to identify. (See appendix 2) These were connected to the camera angles and editing of shots (Jadwin 2012), such as whether the angles enhanced the point of view of a particular subject, whether the setting was fixed, if the film scenes presented actions chronologically and if they illustrated the theme in the song lyrics, or if different themes were introduced. More specifically, the learners were asked to observe whether these visual features elaborated on, underlined or contrasted with the theme of the song. In other words, Approach 2 studied how a song artist creates a multimodal "artistic voice", and tried to make learners aware of certain visual effects. 
Examples related to Text 1 were provided in the introductory session, such as how the camera angle constantly shifts from the male performing artist on stage to a main female character on holiday, thus alternating the focus. The camera also zooms into close-ups of the artist's face, the woman, other participants and various body parts. By focusing on their eyes, the shots move from the performer's point of view to that of the female character. The film is edited to show crossing lines of action occurring at different times and places; the portrayed locations alternate rapidly between mainly black and white shots of the female figure, a Miami airport, a motel, party scenes, beach and boat scenes, and contrasting colour shots of the artist on stage, sometimes also the musicians and a dancing audience. Another device is the way two clips are superimposed on each other. The total visual effect is dizzily hectic as is the performance of the song with its staccato lyrics and rhythm. The video complements and elaborates on the theme of the song, i.e. partying in a young jet-set, while at the same time highlighting the performing artist.

\section{Procedures for questionnaires and written assignment}

The first questionnaire was handed out after the introductory lesson. (See appendix 3) It contained six questions where the learners were asked, among other things, about their affinity to pop music, their previous experience of analysing the theme or other aspects of pop songs and/or poetry, whether they were familiar with the terms: idioms, non-standard language, intertextuality, visual effects, musical genres, artistic voice and also about their preferred learning styles. A few weeks after the final written task, they were given the second questionnaire with five questions, most of which were similar to those in the first questionnaire, only in the light of their experience of the project and their reactions to the project. (See appendix 4)

In the writing task, Group A and Group B were given the same assignment and asked to analyse the lyrics and music video of Text 5. They received a copy of the lyrics and watched a performance by the artist on YouTube. The instructions stated: "You will hear "Firework" performed by Katy Perry twice. Write a 300-500 word analysis of Katy Perry's song and make use of some or all of the key words provided." The seven key words were: musical genre, theme, idioms, non-standard English, intertextuality, visual effects and artistic voice. The pupils' texts were assessed by the teacher trainer and allocated one point according to each of the following criteria:

- identification of an example of a key word category in the text or the video

- conversion of a non-standard expression into standard English

- explanation of an idiom

- a personal evaluation or interpretation in terms of a key word

Fuller explanations, evaluations and interpretations were granted two points. The results and discussion of the results are presented in the following section.

\section{Results}




\section{Results of written task}

The resulting distribution in relation to reference to the seven key word categories is presented in Table 1 below. The Table shows the extent to which Group A with 15 pupils and Group B with 13 pupils made use of the seven key words provided in the instructions to the written assignment. Two pupils were absent in Group B.

Table 1: Number of pupils who used each key word

\begin{tabular}{|l|l|l|l|l|l|l|l|l|}
\hline Group & n. & Genre & Theme & Idioms & $\begin{array}{l}\text { Non- } \\
\text { standard }\end{array}$ & $\begin{array}{l}\text { Intertext } \\
\text {-uality }\end{array}$ & $\begin{array}{l}\text { Visual } \\
\text { effects }\end{array}$ & $\begin{array}{l}\text { Artistic } \\
\text { voice }\end{array}$ \\
\hline A & 15 & 11 & 13 & 14 & 13 & 3 & 11 & 3 \\
\hline B & 13 & 11 & 13 & 9 & 9 & 1 & 12 & 2 \\
\hline
\end{tabular}

The results were broadly similar in both groups. Several individuals used all the key words, but many pupils omitted one or more of them. Theme was the best represented category as it was used by everyone, bar two in group A. At the bottom end, intertextuality and artistic voice were the two categories that were poorly represented in both groups. Three divergences at group level are worthy of note: 1) fourteen pupils in Group A had identified and/or explained some idioms, but only nine pupils in Group B had done so; 2) thirteen in Group A had made reference to non-standard usage whereas only nine in Group B had done so; 3) all, bar one, in Group B referred to visual effects while four in Group A had not done so.

The distribution of points awarded to each group on the written assignment for each category is set out in Table 2 below. This shows the total number of points for the pupils who had referred to particular key words in one or more ways: identifying, converting, explaining, evaluating or interpreting.

Table 2: Number of points awarded for use of key words

\begin{tabular}{|l|l|l|l|l|l|l|l|l|l|}
\hline Group & n. & Genre & Theme & Idioms & $\begin{array}{l}\text { Non- } \\
\text { standard }\end{array}$ & $\begin{array}{l}\text { Intertext- } \\
\text { uality }\end{array}$ & $\begin{array}{l}\text { Visual } \\
\text { effects }\end{array}$ & $\begin{array}{l}\text { Artistic } \\
\text { voice }\end{array}$ & Total \\
\hline A & 15 & 13 & 49 & 71 & 50 & 8 & 34 & 5 & 230 \\
\hline B & 13 & 12 & 55 & 41 & 34 & 3 & 60 & 2 & 207 \\
\hline
\end{tabular}

The four categories gaining most points in both groups were: idioms, theme, visual effects and non-standard language. The pupils in both groups appeared highly engaged in their comments and interpretations of the theme as some quotations illustrate. One wrote the song was: "about stepping out in the real world and showing yourself as the one you truly are", another: "People are great and explosive just like a firework", and a third wrote: "the song is abote you shold never give up but instad you have to open up and trust yourself'(sic) and yet another wrote that the theme was: "Be yourself, no matter what." Group A had spotted and explained a great many idioms. One for example wrote: "Shoot across the sky' means you don't hold back", another commented on the title "Firework" saying: "She means that something small can be great if it only 'explodes'," and another perspicaciously pointed out: 
"The song is all in all just a lot of idioms." Although Group B had also found many idioms, they provided far fewer explanations.

Many in both groups found all the non-standard forms, in particular: "em", "gonna" and "gotta", but Group A had spotted most instances and converted more than Group B into standard English usage. On the other hand, Group B had the most detailed analysis of visual effects and/ or linked the video to the lyrics. One comment was that the camera angle was "all over the plays" (sic) and pointed to the close-ups of the artist, Katy Perry, and the high shot of people dancing. Another in Group B pointed out that when the camera zoomed-in on Katy Perry's face, it was "when she repeated words". Yet another wrote: "When the people in the video is on the way to feel better, it came a firework out of them." One had noticed that when certain scenes were shot, each "adds and fits to the song - shows us what the song is about."

The three categories that had the lowest number of responses in both groups were: genre, intertextuality and artistic voice. Genre was in most cases merely identified as 'pop'. Only three parts of the text were identified as containing intertextual references by pupils in both groups. For instance, "celebrate like the $4^{\text {th }}$ of July" was seen as referring to a cultural event by three pupils, "let it shine" as an allusion to the Bible by one, and "House of cards" as a reference to the nursery tale, The Three Little Pigs by three pupils. Comment on artistic voice was limited to a very few who evaluated it as "good".

The mean of the total individual scores was 15 . The highest total individual score was 24 points, achieved by three learners, and one learner had the lowest total score of five points. Individual responses varied considerably, ranging from solely identifying a key phenomenon to identifying, converting, evaluating and explaining the wider significance in relation to the theme or performance of the song.

\section{Discussion of writing task}

Group A gained more points in sum than Group B, but all fifteen pupils in Group A had been present and answered the written assignment, whereas two in Group B were absent. Hypothetically, if twice the mean score of 15 points were added to the total score for Group B to compensate for those absent, the figures would be 230 and 237 points for A and B respectively. Consequently, it seems reasonable to claim that there is little difference of note between the total scores of the two groups.

Some correspondence is evident between the two sets of results in Tables 1 and 2. Group A was the group which followed Approach 1, where lexico-grammatical features of the pop lyrics, related to idioms, non-standard usage and intertextuality, were in focus. As has been pointed out, the data showed a larger number of pupils in Group A made use of idioms and non-standard usage in particular, and they also achieved the highest scores in these two categories. The fact that Group A followed Approach 1 would seem to account for this, rather than the fact that two more pupils in that group did the writing task. In Group B, which followed Approach 2, where close listening and visual effects were in focus, a larger number of pupils made use of visual effects as a key word category, and achieved a considerably 
higher number of points. This too would appear to be related to the approach used where camera angles and shots were focused on.

The low number of points in both groups for the categories of intertextuality and artistic voice would appear to indicate that the pupils either had difficulty finding examples of intertextuality in Text 5 and in identifying distinguishing features of Katy Perry's artistic voice, or they had a poor understanding of these concepts, or both. Many appeared to consider "pop" a satisfactory answer to the question of genre, and indeed pop may be viewed as a specific musical genre.

Analysis using Approach 1 intended to highlight lexico-grammatical features that help create a distinctive artistic voice. Using idioms taps into a rich ore of language that adds colour to a text. Identifying common non-standard forms, such as $-s$ dropping, double and multiple negation, copula deletion, morphological change and special vocabulary raises awareness of the range of linguistic forms available for expressing personal and/or regional identity. Making intertextual allusions presents yet another field of self-expression. In other words, by analysing and interrogating the song texts using this approach, it was possible to highlight the individuality of the lexico-grammatical choices adopted by the songwriters. Results on the written task appear to document slightly greater awareness of these particular features in Group A.

Approach 2 involved 'recycling' the vocabulary in the lyrics when reconstructing the chorus and completing the gapped version of the text, followed by group discussion about the theme and the effect of different film techniques after both close listening and observation. However, close listening was greatly undermined as smart phones were surreptitiously used to access the text online, eliminating the need for recall. Despite this set-back, the results for the group on the writing task appear to document raised awareness of visual effects in Group B.

All in all, though clearly no statistical evidence can be drawn from the figures in a small study of this kind, the results of the written assignment appear to confirm that employing a different teaching and learning focus had some effect at the time. This is in accordance with the expectation stated above concerning the possible consequence of following different approaches. I will now turn to the data from the pupils' responses on the questionnaires.

\section{Results of questionnaires}

Analysis of the first questionnaire (Q1) showed that both groups of pupils had broadly similar standpoints at the outset of the pop music project (See appendix 5). Since pop music was widely defined in the introductory lesson as including all forms of popular music, it appeared that almost all of the learners, 27 of the 29 who responded, were interested in and listened to pop music. However, one individual in Group A wrote: "I hate it" and preferred to listen to classical music, as did another one in Group B, while two in Group A liked both classical music and pop. Some of the pop genres they mentioned as their favourites: "pop", "dubstep", "punk", "metal" and "rock", did not overlap with the genres in the selected texts. But the

response: "I love it all!" seemed to correspond to the amount of time that many spent listening to it, since 20 of them answered average or above. In other words most pupils were in the 
category of frequent listeners to popular music, but only a few in the avid or averse categories.

Most appeared to be familiar with analysing pop music or poetry in some way although three commented that they had not done so before. All, bar three, stated they had an understanding of analysing by themes, rhythm, etc. All, bar one, had some understanding of at least one key word category, idioms, non-standard language, etc. Indeed, eleven indicated an understanding of between two and four categories. Further, intertextuality and non-standard language rated highest in Group A, with six and five responses respectively. Idioms and nonstandard language rated highest in Group B with seven responses for each. In Q1, Group A gave highest preference to an auditory learning style, whereas Group B rated auditory, kinesthetic and visual learning styles equally highly. The main difference between the groups in Q1 was that Group A appeared to have more confidence than Group B as only three answered 1-2, i.e. below average, whereas seven in Group B answered below average, with respect to how confident they were about analysing pop texts/poetry.

From the first to the second questionnaire (Q2), the degree of response concerning the pupils' understanding of the key words had altered as Table 3 shows. (See also appendix 6)

Table 3: Number of individual responses to each key word on Q1 and Q2

\begin{tabular}{|l|l|l|l|l|l|l|l|l|}
\hline $\begin{array}{l}\text { Pupils: } \\
\text { Questionnair }\end{array}$ & n. & Idioms & $\begin{array}{l}\text { Non- } \\
\text { standard }\end{array}$ & $\begin{array}{l}\text { Intertext- } \\
\text { uality }\end{array}$ & $\begin{array}{l}\text { Visual } \\
\text { effects }\end{array}$ & $\begin{array}{l}\text { Musical } \\
\text { genre }\end{array}$ & $\begin{array}{l}\text { Artistic } \\
\text { voice }\end{array}$ & $\begin{array}{l}\text { Total } \\
\text { responses }\end{array}$ \\
\hline Group A: Q1 & 14 & 4 & 5 & 6 & 3 & 4 & 3 & 25 \\
\hline Group B: Q1 & 13 & 7 & 7 & 3 & 2 & 3 & 1 & 23 \\
\hline Class: Q1 & 27 & 11 & 12 & 9 & 5 & 7 & 4 & 48 \\
\hline Group A: Q2 & 14 & 13 & 11 & 9 & 1 & 2 & 1 & 37 \\
\hline Group B: Q2 & 11 & 8 & 9 & 7 & 8 & 4 & 3 & 39 \\
\hline Class: Q2 & 25 & 21 & 20 & 16 & 9 & 6 & 4 & 76 \\
\hline
\end{tabular}

There were far more responses to the key words in Q2, despite two more pupils being absent when the questionnaire was given, and despite one pupil in Group B leaving this particular question unanswered. The points for: idioms, non-standard usage and intertextuality, had risen most. At group level, idioms rated highest in Group A, followed by non-standard language and intertextuality, with 13, 11 and 9 responses respectively. In Group B, non-standard language with 9 responses was marginally ahead of idioms and visual effects with 8 each.

Further analysis of Q2 showed that 21 out of 26 respondents now felt more confident about analysing pop songs, though once again Group A emerged as more confident than Group B. While one pupil did not feel more confident in Group A, four did not do so in Group B. This corresponds to the finding that Group A found their approach more interesting than Group B had done; twelve out of fourteen in Group A gave scores of 3 - 5, i.e. average and above, compared to only eight out of twelve in Group B. The widely-held verdict in both groups was that listening was the learning style that the project had appealed to most, with 
nine respondents and seven respectively in $\mathrm{A}$ and $\mathrm{B}$; this was followed by five respondents for viewing in Group B.

\section{Discussion of questionnaires}

The most interesting findings in the questionnaires were the larger number of responses in both groups to the seven key word categories from Q1 to Q2. Bearing in mind that the small number of respondents rules out the possibility of drawing any firm conclusions about learning outcomes, this seems to be an indication that the general level of awareness to these aspects had risen in the whole class. The divergence between the groups, with regard to which categories gained highest response in Q2, links up to some degree with the different approaches each group pursued; the number of responses to non-standard had increased most in Group A, and the number of responses to visual effects had increased most in Group B. Another result to emerge from a comparison of the data in the questionnaires was that a large majority felt more confident about analysing pop music. Some made comments such as: "It was fun listening and analysing music," and "Fun to do something different," and one indicated approval by decorating his answers to Q2 with heart symbols. These statements do not mean that a change has occurred, but indicate that the learning environment was positive and this may have incurred learning benefits for some of the pupils in line with what the affective filter hypothesis and socio-cultural theory maintain.

A more disturbing finding was that one third of Group B did not share such positive standpoints; on the contrary they thought the project was of below average interest. The negative responses from these pupils in Group B had surprised the partner teacher. While working with the project, the teacher had the impression that the pupils looked forward to the "pop lessons" on Fridays, wondering about what pop song they would be going to analyse. However, having laptops and mobile phones available most of the day, even at school, often makes concentration and engagement in tasks difficult. Perhaps finding lexico-grammatical features was more familiar and less elusive for the pupils in Group A than finding visual effects was for those in Group B. Perhaps the failure of close listening as a means to elicit the text due to covert use of smart phones reduced the value of Approach 2 for some pupils in Group B. Other possible explanations were that having a new teacher, the teacher trainer, may have affected their level of participation and interest, or the choice of music may have "turned them off". Despite their lack of interest, the Q2 data showed that most of these pupils in Group B had nevertheless indicated that they had a higher level of understanding of several key categories at the end of the project.

As has been pointed out already, a study of this size and length is too limited to warrant any claim that the pupils involved had achieved definite learning outcomes. Hopefully though, it is not an overstatement to postulate that using popular music texts and videos had stimulated the learning environment and possibly enhanced learning for many of the pupils. In accordance with the pre-study expectation, the divergences and correspondences that emerged appear to indicate that the different approaches influenced the learners in both groups to some extent, raising their general understanding of how to analyse 
selected features of pop music. No claim can be made that this study alone would lead to changes in their perception of pop music videos or in their involvement in their language learning, but the different approaches did apparently lead to different outcomes at the time. Were this investigation to be conducted again, random case studies of individual pupils at a later date might have shed more light on how the pupils experienced the project.

\section{Conclusion and implications}

The rationale motivating the design of this research model was three-fold: firstly, to stimulate pupils' involvement in their language learning, secondly, to provide an impetus for the partner teacher and teacher trainer to continue their professional development, and lastly, to work towards attaining certain competence aims in English in LKO6 using less traditional language resources. The study of lexico-grammatical and multimodal features in pop lyrics has proved to be a way of linking form and content in line with SFL theory. Classroom discussions, as well as results, indicated that many of the pupils felt involved in the project in line with intercultural theory; likewise the partner teacher and teacher trainer agree that they have been engaged in professional development related to ELT. The project was of relevance with regard to working towards meeting some competence outcomes in the curriculum connected to the relationship between vocabulary, situation and genre. The implications of this action research is therefore that such investigations are worth embarking on, although additional research is required to see if the aim of action research proposed by Oxford, namely to provide "new insights for positive educational change" (2011: 234), was actually reached.

There is nothing radically new about using popular music as a classroom resource in ELT, as a supplement to the textbook. However, pop music represents a vital element of youth culture, and this vitality can probably be exploited far more in the classroom setting. Exploring linguistic resources and visual effects offers a rich vein of investigation that learners can pursue even further in collaboration with their teacher. Indeed, as a result of the project it was quite natural to have a follow-up task where the learners selected a song of their own choice. The task was to present their findings in an oral presentation of the artist/ songwriter, the lyrics and the music video. Since the AR project started quite early in the school year, most of the learners preferred to work in pairs; they seemed more confident about presenting their findings to the whole class when working with another person they knew. On the whole, they did well, and they chose a great variety of songs, including lyrics by Eric Clapton, Eminem, Bob Marley, Michael Jackson among others. They were able to find lots of examples of non-standard usage, idioms and intertextual references, and they also commented on the videos. For some pupils, this was the part that was appreciated most; one pointed out on Q2: "I thought it was very fun when we analysed our own texts and songs." The teacher and the pupils concluded that the follow-up task was a good way of revising and summing up what they had learned during the project period.

Another possible follow-up task might be to carry out a similar investigation comparing the extent of non-standard usage in the lyrics of certain well-known pop artists or in certain musical genres, such as rap, country and heavy metal. As the results of the writing 
task showed, one group achieved higher scores than the other in certain categories, a repeat study with new groups of pupils could be conducted to see if the results were replicated. Indeed, as many curriculum aims are broadly similar through $8^{\text {th }}$ grade to $\mathrm{Vg} 1 / \mathrm{Vg} 2$, i.e. from lower to upper secondary, the project may be implemented in all of these age groups. The model should also be viable with L1 pop lyrics as the textual material.

Although not all of the learners saw the point of the project, several pupils mentioned, on the questionnaire and in class, that they found taking part in this kind of language study engaging. Pop music would appear to be an underexploited resource in ELT classrooms in Norwegian secondary schools. The description of action research presented here along with the suggested song texts may encourage other teachers of English to carry out their own small-scale study. They may even find they have hit a goldmine. The partner teacher and teacher trainer can recommend others to embark on AR as this kind project enables positive collaboration to take place between schools and higher educational institutions.

\section{References}

Amazon MP3. (2013). Retrieved 05.03.13 from: http://www.amazon.com/MP3-MusicDownload/b?ie $=$ UTF8\&node $=163856011$

Cohen, L., Manion, L. \& Morrison, K. (2011). Research Methods in Education. $7^{\text {th }}$ edn. New York: Routledge.

Dörnyei, Z. (2001). Motivational Strategies in the Language Classroom. Cambridge: Cambridge University Press.

Gairns, R. \& Redman, S. (1986). Working with Words: A guide to teaching and learning vocabulary. CUP.

Grabe, W. \& Stoller, F. L. (2002). Teaching and Researching Reading. Harlow, Essex: Pearson Education.

Hughes, A., Marjan, H. \& Taylor, N. (2012). Action research in TEYL: Reflections on the global picture from 1996 to 2010. In Hasselgreen, A., Drew, I. \& Sørheim, B. (eds.). The Young Language Learner: Research-based insight into teaching and learning. Bergen: $\quad$ Fagbokforlaget, 161-176.

James, P. (2001). Teachers in Action: Tasks for in-service language teacher education and development. Cambridge: Cambridge University Press.

Jadwin, L. (2012). Film Editing PPt. Retrieved 23.10.12 from: http://:www.ppt2txt.com/r/ $39 c c 5 e 57 /$

Krashen, S. D. (1987). Principles and Practice in Second Language Acquisition. London : Prentice-Hall International.

Knowles, B. (2008). If I Were A Boy. On the album I am ...Sasha Fierce. Retrieved 21.01.10 from: http://www.azlyrics.com/lyrics/beyonceknowles/ifiwereaboy.html and from: http://www.myspace.com/video/beyonce/if-i-were-a-boy/47760961

Lantolf, J. P. \& Thorne, S. L. (2006). Sociocultural Theory and the Genesis of Second Language Development. Oxford: Oxford University Press.

Mehta, N. K. (2009). Vocabulary teaching: Effective methodologies. On The Internet TESL Journal, Vol. XV, No. 3. Retrieved 22.01.2010 from: http://iteslj.org/Techniques/

Mehta-Vocabulary.html 
Ministry of Education and Research. (2006). The Quality Framework. Oslo: Norwegian Directorate for Education and Training. Retrieved 22.10.09 from: http://www.udir.no/ upload/larerplaner/Fastsatte_lareplaner_for_Kunnskapsloeftet/ prinsipper_lk06_Eng.pdf Ministry of Education and research. (2006). English subject curriculum. In The National Curriculum for Knowledge Promotion in Primary and Secondary Education and Training (LK06), Oslo: Norwegian Directorate for Education and Training. Retrieved 22.11.12 from: http://www.udir.no/Stottemeny/English/Curriculum-inEnglish/_english/Upper-secondary-education-/

Organisation for Economic Cooperation and Development. (2005). Teachers Matter: Attracting, developing and retaining effective teachers. Paris: OECD. Retrieved 14.10.09 from: http://www.oecd.org/dataoecd/39/47/34990905.pdf

Oxford, R. L. (2011). Teaching and Researching Language Learning Strategies. Harlow, Essex: Pearson.

Perry, K. (2012). Firework. On the album Teenage Dream, Capitol Records. Retrieved 12.12.12 from: http://www.directlyrics.com/katy-perry-firework-lyrics.html and from: http://www.youtube.com/watch?v=QGJuMBdaqIw

Read, J. (2000). Assessing Vocabulary. Cambridge: Cambridge University Press.

Schoepp, K. (2001). Reasons for using songs in the ESL/EFL classroom. In The Internet TESL Journal, Vol. VII, No.2. Retrieved 03.04.2009 from: http://iteslj.org/articles/ schoepp- songs.html

Spaventa, L. (1983). What is in a song. In Practical English Teaching. December, 33-34.

Teddlie, C. \& Reynolds, D. (2000). The International Handbook of School Effectiveness Research. London: Falmer Press.

Tempah, T. \& Swedish House Mafia. (2010). 'Miami to Ibiza'. On the album Disc-Overy, Parlaphone Records. Retrieved 18.10.12 from: http://rapgenius.com/lyrics/Tinietempah-ft-swedish-house-mafia/Miami-2-ibiza and from: http://www.youtube.com/ watch? $\mathrm{v}=\mathrm{LCH} 1 \mathrm{AsUydSc}$

Tempah, T. \& Turner, E. (2010). Written in the Stars. On the album Disc-Overy. Parlaphone Records. Retrieved 18.10.12 from: http://www.directlyrics.com/tinie-tempahwritten-in-the-stars-lyrics.html and from: http://www.youtube.com/watch? annotation_id=annotation_573006\&v=YgFyi74DVjc \&feature $=\mathrm{iv}$

Vygotsky, L. S. (1978). Mind in Society. In M. Cole et al. (eds.).The Development of Higher Psychological Processes. Cambridge, Mass.: Harvard University Press.

West, K. \& Jenkins, J. (2008). Amazing. On the album 808 's \& Heartbreak Lyrics. Retrieved 21.01.10 from: http://www.elyrics.net/read/k/kanye-west-lyrics/amazing-lyrics.html and from: http://www.youtube.com/watch? $\mathrm{v}=\mathrm{PH} 4 J P g V D 2 S M \&$ feature $=$ related 


\section{APPENDIX 1}

\section{Text 1}

'Miami 2 Ibiza', Tinie Tempah, featuring Swedish House Mafia

She said she likes my watch

But she wants Steves AP

And she stay up all hours watching QVC

She said she loves my songs

She bought my MP3

And so I put her number in my bold BB

I got a black BM

She got a white TT

She wanna see what's hiding in my CK briefs

I tell her "Wear suspenders and some PVC"

And then I'll film it all up on my JVC

Scene one

Everybody get in your positions

Pay attention, and listen

We're tryna get this all in one take

So let's try to make that happen

Take one

Action

She pose for FHM

She like my black LV

We spilling LPR up on my APC

I'm in my PRPS and my Nike SB's

Raving with SHM

London to NYC

I got my Visa and my Visa

A diva and her dealer

Bitch I'm up on the guest list

With the Swedish House Mafia

You can find me on a table

Full of vodka and tequila

Surrounded by some bunnies

And it ain't fucking Easter

I'll wake up in the morning

With a mild case of amnesia

With a girl that like a girl

Like Lindsay Lo and Queen Latifah

If you niggas are balling

Then boy I must be FIFA

And that's standard procedure

From Miami to Ibiza

Yeah

From Miami to Ibiza 


\section{APPENDIX 2}

\section{TOOLS FOR ANALYSIS OF VISUAL IMAGES}

Try to see whether the images on the video support the song lyrics and how. Look for:

\section{A. CAMERA TECHNIQUES:}

* Level camera angle: the camera angle is even with the subject and neutral

* Low camera angle : looks up at the subject and may make it look important and powerful

* High camera angle : looks down on the subject and may make it look small, weak or unimportant

* Zooming: move closely towards the subject

* Panning : a steady sweeping movement from one point to another

\section{B. RELATIONSHIPS BETWEEN SHOTS (\& LYRICS):}

* Space: same physical setting or different settings

* Time: chronological, flashback, flash-forward

* Duration: the length of a shot establishes the speed of actions

* Editing:

* Continuity : elements connected - events may seem natural

* Discontinuity: elements not connected - events may seem strange

* Pointofview : moves from one character's POV to another object's

* Fade-in: from empty screen to image or fade-out from image to empty screen 


\section{APPENDIX 3 \\ POP MUSIC PROJECT QUESTIONNAIRE 1 : October, 2012}

Name:

1. What is your favourite kind of music?
a. $\quad$ Pop $\square$
b. Classical $\square$
C. Both $\square$

Comment:

2. How much time do you spend listening to pop music on a scale from 1-5?

1. None $\square$

2. Some (once a day) $\square$

3. Average (twice - thrice a day) $\square$

4. Often (several times a day) $\square$

5. Extremely often (many hours several times a day) $\square$ Comment:

3. How have you analysed pop texts/ poetry previously?
a. Themes $\square$
b. Rhythm $\square$
C. Rhyme $\square$
d. Line by line $\square$
e. Other approaches: $\square$

Comment:

4. How confident are you about analysing pop texts/poetry on a scale from 1- 5?
1. Not confident:
2. A little confident:
3. Average
4. Very confident $\square$
5. Extremely confident $\square$

Comment:

5. Do you have more understanding than previously about the following?
a. Idioms $\square$ 

b. Non-standard language $\square$
C. Intertextuality $\square$
d. Visual effects $\square$
e. Musical genres $\square$
f. Artistic voice $\square$

Comment:

6. Which learning style do you generally prefer?
a. Auditory: listening
b. Kinesthetic: physical activity $\square$
C. Visual: viewing
d. Combination:

Comment:

\section{APPENDIX 4}

\section{POP MUSIC PROJECT QUESTIONNAIRE 2 January, 2013}

Name:

1. Which approach have you used to analyse pop music?
a. Approach $1 \square$
b. Approach 2 ㅁ

2. How interesting did you find the approach on a scale from 1- 5?
a. Not interesting $\square$
b. Quite interesting $\square$
c. Average $\square$
d. Very interesting $\square$
e. Extremely interesting $\square$
f.

Comment:

3. Do you now feel more confident about analysing pop lyrics?

$$
\begin{gathered}
\text { Yes } \\
\text { No } \\
\text { Comment : }
\end{gathered}
$$

4. Do you have more understanding than previously about the following? 

a. Idioms $\square$
b. Non-standard language $\square$
C. Intertextuality $\square$
d. Visual effects $\square$
e. Musical genres $\square$
f. Artistic voice $\square$

Comment:

5. Which learning style did the project appeal most to?
a. Auditory: listening
b. Kinesthetic: physical activity $\square$
C. Visual: viewing
d. Combination: $\square$

Comment: 


\section{APPENDIX 5}

\section{GROUP RESULTS FROM QUESTIONNAIRE 1, 25.10.12}

GROUPA (n.15) / GROUP B (n.14)

1.What is your favourite kind of music?

e. Pop $\square 12 / 13$

f. Classical $\square$ 1/1

g. Both $\square 2 / 0$

COMMENTS: Group A: I like most types (Rihanna, Morrison, etc). / I love it all! / This excludes a lot./ Bethoven/Metal // Group B: I like the music on the radio (NRK MP3) / I like rock and punk better than pop. / Listening to rap \& dubstep / Rap

2.How much time do you spend listening to pop music on a scale from 1- 5?

1. None $\square$ 2/1

2. Some (once a day) $\square 2 / 3$

3. Average (twice - thrice a day) $\square$ 2/3

4. Often (several times a day) $\square 7 / 6$

5. Extremely often (many hours several times a day) $\square 2 / 0$

NO ANSWER: 1

COMMENTS: Group A: I also sleep with music on. / I hate it. // Group B: 1-3 hours daily

3.How have you analysed pop texts/ poetry previously?
a. Themes $\square 7 / 8$
b. Rhythm $\square$ 4/2
c. Rhyme $\square \mathbf{1} / 2$
d. Line by line $\square 4 / 2$
e. Other approaches: $\square 1 / 0$

NO ANSWER: 2 / 1

COMMENTS: Group A: favorite hobby / I have not / I have never analysed song texts before. // Group B: I haven't done it so much.

4.How confident are you about analysing pop texts/poetry on a scale from 1- 5?

1. Not confident $\square 2 / 3$

2. A little confident $\square 1 / 4$

3. Average $\square 8 / 7$

4. Very confident $\square 3 / 0$

5. Extremely confident $\square 1 / 0$

COMMENT: Group A: - // Group B: I really don't know yet.

5.Do you have more understanding than previously about the following?

f. Idioms $\square$ 4/7

g. Non-standard language $\square 5 / 7$

h. Intertextuality $\square 6 / 3$

i. Visual effects $\square \mathbf{3} / 2$

j. Musical genres $\square$ 4/3

K. Artistic voice $\square$ 3/1

NO ANSWER: 1 / 1

COMMENT: Group A: I knew a lot about non-standard before. // Group B: 0 6.Which learning style do you generally prefer?

I. Auditory: listening $\square$ 9/5 
m. Kinesthetic: physical activity $\square 4$ / 1

n. Visual: viewing $\square 5 / 4$

o. Combination: $\square 4 / 8$

COMMENTS: Group A: It depends on the task. // Group B: It depends on the task. / Taking notes / Taking notes / I would like to see the text while listening. / Look to the lyrics. 


\section{APPENDIX 6}

\section{GROUP RESULTS FROM QUESTIONNAIRE 2 ： January, 2013}

GROUPA (n.14) / GROUP B (n.12)

1. Which approach have you used to analyse pop music?

a. Approach $1 \square 14$

b. Approach $2 \square 12$

2. How interesting did you find the approach on a scale from 1- 5?

1. Not interesting $\square 2 / 1$

2. Quite interesting $\square \quad 5$

3. Average $\square 7 / 4$

4. Very interesting $\square 3 / 2$

5. Extremely interesting $\square 2 / 0$

Comments: Group A: It was fun listening and analyzing music / Modern music that I liked! Impressed / I don't like it / I cannot see the point in this learning /It was funny 团 (= heart symbol) // Group B: Fun to do something different/ I thought it was very fun when we analysed our own texts \& songs/The classes was boring but analyse a teks my self is interesting for the presentation/I didn't learn anything / I did'nt find it interesting

3. Do you now feel more confident about analysing pop lyrics?

Yes : $13 / 8$

No: $1 / 4$

Comment: Group A: 0 // Group B: I knew how to do it before the class

4. Do you have more understanding than previously about the following?
C. Idioms $\square 13 / 8$
d. Non-standard language $\square$ 11/9
e. Intertextuality $\square 9 / 7$
f. Visual effects $\square 1 / 8$
g. Musical genres $\square 2 / 4$
h. Artistic voice $\square$ 1/ 3

No answer: 0 / 1

Comment: Group A: a,b,c the most/ b] G] We didn't do the last three ones // Group B: No, we didn't do anything

5. Which learning style did the project appeal most to? 
i. Auditory: listening $\square$ 9/7

j. Kinesthetic: physical activity $\square \mathbf{3}$ / 0

k. Visual: viewing $\square 2 / 5$

I. Combination: $\square$ 1/ 1

Comment: Group A: b] // Group B: 0 